\title{
Differential Change in the Prevalence of the Ascaris, Trichuris and Clonorchis infection Among Past East Asian Populations
}

\author{
Xiaoya Zhan', Hui-Yuan Yeh1, Dong Hoon Shin², Jong-Yil Chai, ${ }^{3,4}$ Min Seo ${ }^{5}$, Piers D. Mitchell,** \\ 'School of Humanities, Nanyang Technological University, 48 Nanyang Ave, 639818 Singapore; 'Institute of Forensic and Anthropological Science, \\ Seoul National University College of Medicine, Seoul, 03080 Korea; ${ }^{3}$ Department of Tropical Medicine and Parasitology, Seoul National University \\ College of Medicine, Seoul, 03080 Korea; ${ }^{4}$ Institute of Parasitic Diseases, Korean Association of Health Promotion, Seoul, 07649 Korea; \\ ${ }^{5}$ Department of Parasitology, Dankook University College of Medicine, Cheonan, 31116 Korea; ${ }^{6}$ Department of Archaeology, University of \\ Cambridge, The Henry Wellcome Building, Fitzwilliam Street, Cambridge, CB2 1QH, UK
}

\begin{abstract}
As we learn more about parasites in ancient civilizations, data becomes available that can be used to see how infection may change over time. The aim of this study is to assess how common certain intestinal parasites were in China and Korea in the past 2000 years, and make comparisons with prevalence data from the 20th century. This allows us to go on to investigate how and why changes in parasite prevalence may have occurred at different times. Here we show that Chinese liver fluke (Clonorchis sinensis) dropped markedly in prevalence in both Korea and China earlier than did roundworm (Ascaris lumbricoides) and whipworm (Trichuris trichiura). We use historical evidence to determine why this was the case, exploring the role of developing sanitation infrastructure, changing use of human feces as crop fertilizer, development of chemical fertilizers, snail control programs, changing dietary preferences, and governmental public health campaigns during the 20th century.
\end{abstract}

Key words: Chinese liver fluke, history, mummy, paleoparasitology, roundworm, whipworm, China, Korea

Comparing the presence of parasites in ancient and modern populations can help us to understand how prevalence of different species can change over time. Here we use this approach to investigate the changes in prevalence of certain nematodes and trematodes in East Asia over the last 1,000-2,000 years, and consider the evidence for why these changes may have occurred when they did. Parasite infection in past populations can be determined by analyzing the intestinal contents of mummies, coprolites (preserved pieces of human faeces), sediment from the pelvis of skeletonized burials, or the contents of latrines. However, the eggs of some intestinal parasites are fragile and may be destroyed by fungi, bacteria and insects in certain environments [1]. Since the best-preserved source of ancient faecal material are mummified bodies [2], we have chosen to use the data from mummies in this study.

- Received 1 August 2019, revised 12 October 2019, accepted 20 October 2019.

*Corresponding author (pdm39@cam.ac.uk)

(c) 2019, Korean Society for Parasitology and Tropical Medicine

This is an Open Access article distributed under the terms of the Creative Commons Attribution Non-Commercial License (http://creativecommons.org/licenses/by-nc/4.0) which permits unrestricted non-commercial use, distribution, and reproduction in any medium, provided the original work is properly cited.
It is not easy to determine accurate prevalence of parasites in past populations as the numbers of surviving individuals are small, and we have to amalgamate data from those who died at different time periods. Furthermore, mummies in East Asia tend to be the remains of wealthy individuals who could afford complex tombs and burial rites that led to preservation of their remains. Therefore, we should be clear that the mummies do not represent the complete range of social status of those who lived in past populations. Nevertheless, by using the evidence that is available, we can make broad estimates of how common different species of parasites appear to have been in past societies, and use this to look for changes over time.

For ancient China, 13 mummies have been recovered and analyzed for intestinal parasites. Their dates ranged from the Warring States period (5th century BCE to 221 BCE) through to the Ming Dynasty (1368 to $1644 \mathrm{CE}$ ). When we look at soil transmitted nematodes, we have shown that Trichuris trichiura was present in $77 \%$ of mummies $(\mathrm{n}=10 / 13)$, and Ascaris lumbricoides in $62 \%(\mathrm{n}=8 / 13)$. If we consider trematodes, Clonorchis sinensis was present in $47 \%$ of the mummies [3]. In 20th century China, the first national survey of intestinal para- 
site infection gathered data from 1988-1992 [4]. The prevalence of roundworm infection was $46 \%$, and of whipworm was $19 \%$. In contrast with the nematodes, C. sinensis infection was very low at just $0.365 \%$ in China (Table 1 ). This shows that the prevalence of Chinese liver fluke fell to low levels by the 1980s, while roundworm and whipworm remained common at that time.

For ancient Korea, 24 mummies have been recovered and their intestinal contents studied for helminths [5]. These mummies are the remains of individuals who died during the Joseon dynasty (1392-1910 CE). When we assessed soil transmitted nematodes, T. trichiura was present in $83.3 \%$ of mummies $(\mathrm{n}=20 / 24)$, and A. lumbricoides in 58.3\% $(\mathrm{n}=14 / 24)$. In the case of trematodes, C. sinensis was present in $25 \%$ ( $\mathrm{n}=$ 6/24) of the Korean mummies [5] (Table 1). In 20th century Korea, national survey statistics for parasite prevalence have been published in 1971 [5]. For A. lumbricoides, prevalence was still as high as $54.9 \%$. However, the prevalence started to fall over the next decade, and by the 1992 report, it had fallen to $0.3 \%$ (Table 1). Similarly, T. trichiura prevalence was high (65.4\%) in the 1971 report, but by 1992 it had fallen to $0.2 \%$. Meanwhile, trematode showed a different pattern. By 1971, C. sinensis prevalence had already fallen considerably to $4 \%$, in contrast with that of Joseon mummy prevalence (25\%). This data demonstrates that the prevalence of Chinese liver fluke in Korea fell earlier than did the nematodes whipworm and roundworm [5].

Taken together, we can see that both in Korea and China, $C$. sinensis infection decreased significantly before we see the same pattern in nematodes. The fact that the same pattern occurred simultaneously both in China and Korea is very signifi-

Table 1. Estimation of Change in Parasite Infection Prevalence in China and Korea

\begin{tabular}{|c|c|c|c|c|}
\hline \multirow[b]{2}{*}{ China } & \multirow[t]{2}{*}{ Parasites } & \multicolumn{2}{|c|}{ Prevalence (\%) } & \multirow[t]{2}{*}{ Odds ratio } \\
\hline & & Ancient $^{\mathrm{a}}$ & $1988-1992^{b}$ & \\
\hline & Ascaris & 62 & 46 & 0.522 \\
\hline & Trichuris & 77 & 19 & 0.07 \\
\hline & Clonorchis & 47 & 0.365 & 0.004 \\
\hline \multirow[t]{4}{*}{ Korea } & & Joseon $^{c}$ & $1971^{d}$ & \\
\hline & Ascaris & 58.3 & 54.9 & 0.87 \\
\hline & Trichuris & 83.3 & 65.4 & 0.379 \\
\hline & Clonorchis & 25 & 4.6 & 0.145 \\
\hline
\end{tabular}

aYeh and Mitchell, 2016 [3]; ' $Y$ u et al., 1994 [4]; ' Seo et al., 2017 [5]; ${ }^{\mathrm{d}}$ Korea Association of Health Promotion, 2012 [36].

'The odds ratio was calculated by dividing the odds of the 1988-1992 group by the odds in the Ancient group. cant. As for the parasite infection data acquired from paleoparasitology and the 20th century national survey, odds ratios of Ascaris, Trichuris, and Clonorchis infections are 0.522, 0.07, 0.004, respectively. Similarly, the same odds ratios of Ascaris, Trichuris, and Clonorchis of Joseon and 20th in Korea are 0.87, $0.379,0.145$, respectively. We might attribute the decrease in the parasite prevalence to the improvements in hygiene (such as clean water and hand washing with soap) or sanitation (flushing toilets and improved sewerage). If that was the case, however, we expect that the fall in nematode infection took place at the same time as the fall in trematodes. Since the trematode prevalence dropped earlier than was the case for nematodes, we must consider alternative explanations.

In Korea, a high infection rate of soil-transmitted parasitism in the Joseon period was closely related to the practice of farmers to recycle night soil as fertilizer for maintenance of their farmlands. Human feces contaminated by Ascaris or Trichuris eggs were used as fertilizer for vegetable farming at that time [6]. The Joseon people's consumption of parasite-egg-contaminated vegetables could have initiated a cycle of soil-transmitted parasitism whereby they were repeatedly re-infected [5]. As long as Korean farmers continued to use night soil as a fertilizer for vegetable growing, the rates of parasitic reinfection would not have dropped much at all in the country. This means that once chemical fertilizers replaced night soil, which followed industrialization, then Ascaris and Trichuris infection was significantly reduced in Korean society [5]. This explains why soil-transmitted parasitism in South Korea was still prevalent among South Korean population in the 1970s, not so different from that of Joseon period. Until the 1970s, the rate of soil-transmitted parasite infection was high because the industrialization of Korea was limited, and chemical fertilizer could not completely replace the manure in the country [7] (Table 2). Therefore, the timing of the drop in nematode infection between the 1970s and 1990s might have been due to multiple factors including the implementation of the parasite prevention and treatment, improving sanitation infrastructure, and the decline in the use of manure in a farming as a result of the spread of chemical fertilizers.

We also need to consider explanations to explain why C. si-

Table 2. Chemical Fertilizer Production in South Korea ${ }^{a}$

\begin{tabular}{lccccccc}
\hline Year & 1965 & 1967 & 1973 & 1976 & 1980 & 1988 & 1994 \\
\hline Production $^{\mathrm{b}}$ & 170 & 1132 & 1568 & 2099 & 3341 & 3848 & 4688 \\
\hline
\end{tabular}

aKorean Statistical Information Service (2019); 'kilotons. 
nensis decreased in prevalence in Korea earlier than did the nematodes. The most likely cause might be the socio-cultural environment of Joseon society. According to the extant historical records, Joseon people enjoyed raw fish dishes more than we thought, causing $C$. sinensis infection to be more frequent than expected [5,8]. Prevalence of C. sinensis would have dropped if people changed their habit of eating raw fish, and chose to cook the fish before it was eaten [8]. Decrease in intermediate hosts due to environmental pollution might also have been a contributing cause of reduced infection rate of $C$. sinensis in the Korean population before the 1970s, though this cannot yet be proven. In contrast with the case for the soiltransmitted parasites, the decrease in C. sinensis infection rate might have occurred with relatively little impact of industrialization and sanitary modernization in the country.

Having considered the evidence from Korea, we can explore possible reasons for the changes in nematode and trematode parasite prevalence in China. The National Health and Family Planning Commission reported that the coverage of sanitary toilets in rural regions of China was just 7.5\% in 1997 but climbed to $78.5 \%$ in 2015 [9]. The fact that sanitary toilets only became common across China after the year 2000 would very likely contribute to the persistence of roundworm and whipworm infection in the region until that time. In China, human and animal feces also appear to have been used as fertilizer at least since the Shang Dynasty (17th Century BCE to 11th Century BCE) [10,11]. Most cities transported the human waste to rural regions as the feces were used as fertilizer or food for fish, especially in southern China [12]. The prevalence of some parasitic diseases among vegetables farmers, such as ascariasis and trichuriasis, reached more than $90 \%$ in the 1980s and 1990s [12]. Before 1949, feces were the dominant form of fertilizer in agriculture. The application of chemical fertilizer gradually increased until it exceeded organic fertilizer in the 1980s [13]. In recent years more than $70 \%$ of the agricultural fertilizer in China was chemical fertilizer [14]. Therefore, it is likely that the shift from farmers using human feces to using chemical fertilizer to improve crop yields matches the timing of the changes in prevalence we see, and so is likely to be an important factor explaining the late decline in nematode infection in China.

In order to assess why Chinese liver fluke became less common in China earlier than did the nematodes, we will assess the role of cooking practices, snail control, health education and medical treatment. We should consider first whether there has been a change in culinary preferences away from eating raw fish to cooked fish, which cannot transmit $C$. sinensis. Consuming raw fish and meat has a long history in China. As early as in Pre-Qin Period (before 221 BCE), people started to consume raw fish [15]. This custom became more and more popular in later periods, starting from the Han Dynasty and reaching its peak in the Sui (581-619 CE) and Tang Dynasties (618-907 CE) [16]. Raw fish and meat were still popular among town dwellers during the Song Dynasty, although using fire to cook was also popular at the same time [17]. After the Song Dynasty, however, consuming raw fish gradually lost its popularity and it had disappeared in most parts of China in the 20th century except for a few populations in Guangdong, Shandong, Fujian, and Heilongiiang $[16,18,19]$. As raw fish became much less popular in the 20th century, it may have played a role in the decrease in the prevalence of Chinese liver fluke during the period.

Next, we must consider the attempts to control freshwater snails in China. Freshwater snails, the first intermediate hosts for $C$. sinensis, are distributed widely in China, with a range of species including Alocinma longicornis, Parafossarulus striatulus, Semisulcospira cancellata, and Bithynia fuchsianus [20]. Chemical and physical methods have both been applied to snail control in China. Chemical methods focused on the applications of molluscicides (e.g. niclosamide and nicotinanilide) [21]. Physical activities to control snails include adjusting agricultural land, filling old irrigation ditches with the freshly dug-out soil, concreting the lining of canals, altering sluice gates, and planting fast grow trees [21-26]. Therefore, it is likely that the efforts to prevent schistosomiasis by killing snails required for its life cycle may also have helped to reduce C. sinensis, as its snail hosts would have been controlled at the same time.

Finally, since the 1970s, policies such as health education, health promotion, environmental reconstructions, and drug therapy have been put into force to control liver fluke in China $[27,28]$. The parasite was once epidemic in Huaiyang County, Henan Province. Before firm measures were taken in 1973, the mean prevalence of liver fluke in Huaiyang reached $10.56 \%$ $(212 / 2,007)$ [29]. Health education and health promotion were conducted widely in this region since 1973 . With a better understanding of liver fluke, the residents adopted appropriate cooking methods, resulting in the decreasing prevalence of $C$. sinensis among snails, fish, cats and dogs [29]. Finally, in 1987, the mean prevalence of $C$. sinensis among the residents in Huaiyang County dropped to $0.69 \%(18 / 2,617)$ and no new 
infection was reported among children during this period [29]. Improving the lavatories and waste disposal treatments (e.g. moving toilets and pig pens away from fish ponds) also helped cut the route of transmission of the eggs of $C$. sinensis. $[30,31]$. Drug treatment of infected individuals is another efficient implement to intervene and control the spread of C. sinensis. A program was conducted from 1990-1992 with repeated examinations and treatments for $C$. sinensis in Rongshu Village, Wuhua County, Guangdong Province; as a result, the infection rate decreased from $29.4 \%(560 / 1,905)$ to $13.9 \%$ in 1991, and to 8.7\% in 1992 [32]. Moreover, chemotherapy programs have been implemented in Guangdong Province (Shunde City), Guangxi, and Heilongjiang; All regions show a decreasing infection rate of liver fluke after the interventions [33-35].

To conclude, we have shown that in both Korea and China, A. lumbricoides, T. trichiura, and C. sinensis infections were all common in ancient populations. However, C. sinensis infection rate appears to have fallen earlier than did Ascaris and Trichuris infections. It appears that in both Korea and China the fall in parasite infection prevalence was not due to improvements in sanitation, but rather due to other complex interacting factors. A. lumbricoides, T. trichiura, and C. sinensis infections were differently influenced by multiple factors such as changing use of human feces as crop fertilizer, development of chemical fertilizers, snail control programs, changing dietary preferences, and governmental public health campaigns during the 20th century.

\section{CONFLICT OF INTEREST}

We have no conflict of interest related to this work.

\section{REFERENCES}

1. Morrow JJ, Newby J, Piombino-Mascali D, Reinhard KJ. Taphonomic considerations for the analysis of parasites in archaeological materials. Int J Paleopathol 2016; 13: 56-64.

2. Camacho M, Araújo A, Morrow J, Buikstra J, Reinhard K. Recovering parasites from mummies and coprolites: an epdemiological approach. Parasit Vectors 2018; 11: 248.

3. Yeh HY, Mitchell PD. Ancient human parasites in ethnic Chinese populations. Korean J Parasitol 2016; 54: 565-72.

4. Yu S, Xu L, Jiang Z, Xu S, Han J, Zhu Y. Chang J, Lin J, Xu F. Report on the first nationwide survey of the distribution of human parasites in China. 1. Regional distribution of parasite species.
Chin J Parasitol Parasit Dis 1994; 12: 241-247 (in Chinese).

5. Seo M, Oh CS, Hong JH, Chai JY, Cha SC, Bang Y, Cha IG, Wi YG, Park JM, Shin DH. Estimation of parasite infection prevalence of Joseon people by paleoparasitological data updates from the ancient feces of pre-modern Korean mummies. Anthrop Sci 2017; 125: 9-14.

6. Kim MJ, Ki HC, Kim S, Chai JY, Seo M, Oh CS, Shin DS. Parasitic infection patterns correlated with urban-rural recycling of night soil in Korea and other East Asian countries: The archaeological and historical evidence. Korean Studies 2014; 38: 51-74.

7. Korean Statistical Information Service. [Internet]; [cited 2019 June 30] Available from: http://kosis.kr/index/index.do.

8. Ki HC, Shin DH, Seo M, Chai JY. Infection patterns of trematode parasites among Joseon people. J Korean Med Assoc 2014; 57: 866-875.

9. NHFPC. China Health and Family Planning Statistical Yearbook. Beijing, China. Peking Union Medical College Press. 2016. (in Chinese).

10. Xu ZY. Handai Nongye: Zhongguo Nongye Jingji De Qiyuan Ji Texing (Han Agriculture: the Formation and Features of Early Chinese Agrarian Economy). Guilin, China. Guangxi Normal University Press. 2005. (in Chinese).

11. Yeh HY, Zhan XY, Qi WY. A comparison of ancient parasites as seen from archeological contexts and early medical texts in China. Int J Paleopathol 2019; 25: 30-38.

12. Ling B, Den TX, Lu ZP, Min LW, Wang ZX, Yuan AX. Use of night soil in agriculture and fish farming. World Health Forum 1993; 14: 67-70.

13. Liu Y, Huang JK, Zikhali P. Use of human excreta as manure in rural China. J Integr Agric 2014; 13: 434-442.

14. Zhou JB. Reconsideration of the changes of plant nutrition from organic fertilizers to chemical fertilizers. J Plant Nutr Fertiliz 2017; 23: 1686-1693 (in Chinese).

15. Zhou S. Notes on Spring and Autumn Annals of Wu and Yue. Shanghai, China. Shanghai Ancient Books Publishing House. 1997 (in Chinese).

16. Wu YY. The history and culture of "Kuai": The origin of sashimi. J Chongqing Univ Educ 2017; 30: 33-36 (in Chinese).

17. Marks RB. China: Its Environment and History. New York, USA. Rowman \& Littlefield. 2011.

18. Anderson EN, Food and Environment in Early and Medieval China. Philadelphia. University of Pennsylvania Press. 2014.

19. Simoons F. Food in China: a Cultural and Historical Inquiry. Boca Raton, USA. CRC Press. 1991.

20. Cai Y, Malacology Generality. Shanghai. Shanghai Scientific and Technical Publishers. 1995. (in Chinese).

21. Yuan Y, Xu XJ, Dong HF, Jiang MS, Zhu HG. Transmission control of schistosomiasis japonica: implementation and evaluation of different snail control interventions. Acta Trop 2005; 96: 191197.

22. Chen X, Wang L, Cai J, Zhou X, Zheng J, Guo J, Wu X, Engels D, Chen M. Schistosomiasis control in China: the impact of a 10year World Bank Loan Project (1992-2001). Bull World Health 
Organ 2005; 83: 43-48.

23. Cheng J, Yang Y, Wang W, Li X, Chen Q. The effect of killing Oncomelania about the Pterocarya stenoptera community on the beaches of the Yangtze River. Hubei Univ Natur Sci Edit 2000; 22: 80-83 (in Chinese).

24. Utzinger J, Zhou XN, Chen MG, Bergquist R. Conquering schistosomiasis in China: the long march. Acta Trop 2005; 96: 69-96.

25. Xu J, Steinman P, Maybe D, Zhou XN, Lv S, Li, SZ, Peeling R. Evolution of the national schistosomiasis control programmes in the People's Republic of China. Adv Parasitol 2016; 92: 1-38.

26. Yu FA, Peng W, Peng Z, Zhang J, Liu L, Peng D. Plant allelopathy effects on Oncomelania hupensis. Chin J Appl Ecol 1996; 4: 407410 (in Chinese).

27. Wang LZ. Current status and future development of parasites control and prevention in China. Chin J Parasitic Dis Control 1988; 1: 2-4 (in Chinese).

28. Wu W, Qian X, Huang Y, Hong Q. A review of the control of Clonorchiasis sinensis and Taenia solium taeniasis/cysticercosis in China. Parasitol Res 2012; 111: 1879-1884.

29. Han CR, Mei SW, Liu F, Li SZ, Ma YX, Wang YZ, Gao GH, Qu MQ. Current status and prevention of liver fluke in Huaiyang County. Henan J Prev Med 1988; 4: 68-70 (in Chinese).

30. Zhang Q, Huang F, Geng Y, Huang D, Li X, Gao S, Zhang R. Relationship between propagation of Clonorchis sinensis and ecolo- gy cultivation. China Trop Med 2009; 9: 1012-1125 (in Chinese) 31. Zhang X, Pei F, Zhang Q, Lin R, Huang S, Wang J, Cen Y, Lu W, Chao B. Current status of environmental sanitation and Clonorchis sinensis intermediate host infection of freshwater aquaculture in partial areas of Guangdong Province. South China J Prevent Med 2010; 36: 9-13 (in Chinese).

32. Chen ZZ, Jing-Zeng W, Liu MZ, Lin D, Pan LX, Yang ZH, Lan $X$, He JY, Liao YK, Zeng MX. Effect of repeated examination and treatment for Clonorchis, hookworm, Ascaris and Trichuris infection control. Chin J Parasit Dis Contr 1995; 3: 211-213 (in Chinese).

33. Choi MH, Park SK, Li Z, Ji Z, Yu G, Feng Z, Xu L, Cho S-Y, Rim $\mathrm{HJ}$, Lee SH. Effect of control strategies on prevalence, incidence and re-infection of clonorchiasis in endemic areas of China. PLoS Negl Trop Dis 2010; 4: e601.

34. Ge T, Li C, Yuan S. A comparative investigation on chemotherapy in the control of clonorchiasis. Chin J Parasitol Parasit Dis 2004; 22: 128-128 (in Chinese).

35. Hong ST, Rim HJ, Min DY, Li X, Xu J, Feng Z, Lee SH. Control of clonorchiasis by repeated treatments with praziquantel. Korean J Parasitol 2001; 39: 285.

36. Korea Centers for Disease Control and Prevention . Korea Association of Health Promotion: Prevalence of intestinal parasites in Korea - The 8th Report. Seoul, Korea. 2012. 
